\title{
Gago, G. (Realizador). (2017). Matria [Filme]. Espanha: Sombriza Films, Ringo Media. \\ GAGo, G. (Director). (2017). MATRIA [FILM]. \\ Spain: Sombriza Films, Ringo Media.
}

\author{
Carla Cerqueira
}

A curta-metragem Matria (2017), uma produção de Sombriza Films (Galiza) e Ringo Media (Catalunha), da autoria do jovem realizador galego Álvaro Gago' [Vigo, 1986] e com o apoio de AGADIC - Agência Galega de Indústrias Culturais, relata um dia na vida de Ramona [Francisca Iglesias Bouzón], uma mulher de cerca de 50 anos, operária de uma fábrica de conservas na zona costeira da Galiza. Trata-se de um filme de ficção, mas que apresenta uma narrativa esteticamente crua que o torna bastante próximo da realidade, trazendo um olhar crítico sobre o mito do matriarcado na cultura tradicional galega.

Esta curta-metragem de 21 minutos traz para a tela o quotidiano de uma mulher anónima que, tal como tantas outras, não costuma estar no papel de protagonista e por isso é frequentemente silenciada ou secundarizada pelas narrativas cinematográficas (Lauzen, 2018). Ramona é um exemplo das mulheres que calam, que suportam, que têm um ritmo de vida intenso e que se sacrificam pelas outras pessoas. Basta olhar para a forma como inicia o filme, com a protagonista apressada para sair para trabalhar, sem ter tempo para cuidar de si, num plano fechado que mostra a vida de extrema dureza exposta no seu rosto. Esta ausência de cuidado de si que remete para a anulação do sujeito marca todo o filme. Este cuidado é sempre transferido para as outras pessoas, visível por exemplo quando atende o telemóvel no meio do trabalho desobedecendo às regras, quando fica sem horário de almoço para ir a casa servir a refeição ao marido ou quando coloca apressadamente o desodorizante porque tem de sair a correr para resolver os problemas da família (filha e neta). As expressões de um certo cansaço e de luta contínua de Ramona sobressaem ao longo da narrativa através de alguns planos fechados utilizados, uma técnica à qual o realizador parece dar destaque.

Ver este filme é ter presente um conhecimento situado, ancorado no contexto geográfico (zona costeira da Galiza e indústria conserveira) e temporal (atualidade marcada pela precariedade laboral), na história (das relações familiares, de género, intergeracionais e profissionais), nas estruturas (sociais, políticas e económicas) e nos atores sociais envolvidos na produção cinematográfica. Numa época em que se vive numa "ilusão de igualdade" (Banyard, 2010) e em que a retórica do pós-feminismo (Tasker \& Negra, 2007) invade as produções mediáticas, onde se incluem as narrativas cinematográficas, esta história visibiliza precisamente as relações de género desiguais bem patentes na sociedade e que são fruto de um sistema patriarcal que continua muito

\footnotetext{
' Ver https://www.alvarogago.com
} 
enraizado. À semelhança do que tem sido feito por alguns investigadores², é nesta ótica que o realizador desconstrói a ideia de matriarcado galego defendida por José Cela e Vicente Risco num livro sobre a vida quotidiana dos galegos nos últimos 200 anos. Ramona é apresentada como uma mulher galega, forte, sacrificada e quase asfixiada pelo seu quotidiano, mas esse seu poder é apenas aparente, pois ela só tenta sobreviver. O seu dia-a-dia é marcado pelo vazio, por uma certa alienação, as quais estão bem retratadas através de um realismo ambiental que marca a estética fílmica desta curta-metragem. Este enquadramento é suportado através de diversos planos em que vemos o rosto da protagonista, a sua expressão de angústia e de desespero. Noutros momentos assistimos ao seu pedalar da bicicleta, que surge como metáfora da vida acelerada que leva e do risco que corre no quotidiano. Além disso, não existe muito diálogo ao longo da narrativa, mas cada palavra remete para uma densidade que não deixa os espectadores indiferentes. As relações de género marcam todo o filme e vão-se cruzando no domínio privado (familiar) e no domínio público (laboral, nos espaços de lazer).

Paralelamente, as relações intergeracionais também estão presentes, nomeadamente através da interação entre avó, filha e neta. Numa sociedade marcada pela precaridade laboral e pela necessidade de entreajuda entre gerações, a avó, Ramona, faz tudo para que as suas descendentes se sintam felizes. Aqui também há uma referência marcante à sociedade de consumo e ao facto de as pessoas valorizarem cada vez mais os bens materiais (traduzida no filme pela importância da prenda de aniversário para a neta).

Este filme também nos fala de relações interpessoais e da (in)comunicação na esfera familiar e profissional. Basta atentarmos para a forma como Ramona se relaciona com o marido. Ela deixa de ter hora de almoço para ir a casa colocar-lhe a comida na mesa e nesta cena denota-se que se trata de algo extremamente mecânico, em que não há o mínimo de comunicação, de diálogo entre os dois. Este ponto faz ressaltar novamente as relações de género assimétricas bem patentes. Também no trabalho a comunicação está por vezes ausente, gerando situações de conflito, marcadas pelas relações de poder/hierarquia. Um exemplo muito visível é o dos insultos da encarregada da fábrica de conservas, que exerce o poder de forma tirana, sem olhar para as funcionárias, todas elas mulheres. Aqui sublinha-se uma atividade profissional que é desempenhada sobretudo por mulheres, mas há um momento no filme em que se vê uma imagem fugaz do chefe da fábrica, um homem e que, uma vez mais, vem mostrar quem detém efetivamente o poder e se encontra no topo da hierarquia.

De realçar ainda que a precariedade e a desumanização do mercado de trabalho, bem como a crise económica estão também presentes neste filme. Pode, por isso, dizer-se que há aqui uma crítica bem presente ao modo de produção vigente na sociedade capitalista, que não permite sequer que as pessoas parem para pensar e se questionar sobre as relações laborais. Esta crítica trespassa o quotidiano laboral da protagonista e cruza também a sua vivência familiar, sobretudo quando se sacrifica para ajudar a filha e a neta.

${ }^{2}$ Ver https://www.elprogreso.es/articulo/noticias/el-mito-del-matriarcado-gallego/20071222165000150353.html https://praza.gal/cultura/lo-mito-do-matriarcado-galego-e-totalmente-falsor 
Apesar de se tratar de uma curta-metragem, este filme discute diversos e complexos temas, sem nunca ignorar a profundidade que estes merecem. Por vezes sente-se que a ficção e a realidade se cruzam e que estão muito próximas de nós. Tal como o realizador tem explicado em diversas entrevistas, a protagonista, Ramona, não é uma atriz profissional. O filme partiu precisamente do contacto que o realizador tinha com Francisca Iglesias Bouzón, que tinha sido empregada do seu avô e que tinha cuidado dele nos últimos anos da sua vida. Ele quis dar-lhe voz, visibilidade, mostrar um exemplo de uma heroína anónima que já conhecia desde criança, que era para ele uma fonte de inspiração, mas que retratava também o quotidiano de muitas outras mulheres. Além disso, as outras atrizes e atores não tinham experiência prévia. No filme entra a irmã e a sobrinha de Francisca Iglesias Bouzón, as mulheres da fábrica trabalham lá, os homens que estão no café também não são atores. Tudo isto aponta, uma vez mais, para linhas difusas entre a realidade e a ficção.

Matria já venceu mais de 40 prémios a nível internacional, de onde se pode destacar o Grande Prémio do júri do Festival de Sundance para curtas-metragens (2018) e a melhor curta metragem de ficção no IndieLisboa (2018). Trata-se de um filme humanista, que fala de esperança, apesar da sua carga emotiva por vezes extremamente pesada e realista. A última cena do filme mostra Ramona com uma expressão que remete para o futuro e para a possibilidade de mudança, numa ótica pessoal, mas também social. Esta é a mudança que se ambiciona, de uma sociedade mais justa, equitativa e menos individualista.

O realizador Alvaro Gago tem referido em entrevistas e na sua página pessoal ${ }_{3}$ que a curta-metragem Matria não tem um objetivo claramente político, mas pretende contar a história de uma mulher desconhecida que cuida de muitas coisas, sobretudo de pessoas. Neste sentido, visa dar visibilidade e permitir o seu reconhecimento público. Contudo, ao assistirmos a este filme encontramos reflexões sobre diversas problemáticas sociais. É de relembrar que desde o seu surgimento, no final do século XIX, que o cinema tem desempenhado precisamente este duplo e importante papel no que concerne, por um lado, ao reforço das relações de poder desiguais existentes na sociedade e, por outro, ao questionamento dos valores e das configurações identitárias dominantes no imaginário individual e coletivo (Marsh \& Nair, 2004). Esta curta-metragem é um exemplo que comprova claramente o poder que as narrativas cinematográficas têm enquanto espaços de questionamento da ordem social dominante, de luta e de resistência social.

\section{REFER̂̂NCIAS}

Banyard, K. (2010). The equality illusion: the truth about women and men today. Londres: Faber \& Faber.

Lauzen, M. (2018). It's a man's (celluloid) world: portrayals of female characters in the 100 top films of 2017. Retirado de https://womenintvfilm.sdsu.edu/wp-content/uploads/2018/02/2017_Its_a_Mans_ Celluloid_World_Report_2.pdf

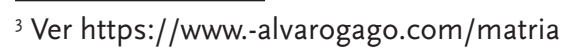


Marsh, R. \& Nair, P. (2004). Gender and Spanish cinema. Oxford, Reino Unido: Berg.

Tasker, Y. \& Negra, D. (2007). Interrogating postfeminism: gender and the politics of popular culture. Durnham: Duke University Press.

\section{NOTA BIOGRÁFICA}

Carla Cerqueira é doutorada em Ciências da Comunicação - especialidade de Psicologia da Comunicação pela Universidade do Minho. Atualmente é investigadora do Centro de Estudos de Comunicação e Sociedade (CECS) e Professora Auxiliar na Universidade Lusófona do Porto. Os seus interesses de investigação incluem género, feminismos e média. Editou e publicou diversos livros, capítulos e artigos nessas áreas de investigação. Mantém um envolvimento ativo com várias associações científicas (inter) nacionais e organizações não-governamentais portuguesas na área da igualdade de género e direitos humanos.

Email: carla.cerqueira@ics.uminho.pt

Morada: Centro de Estudos de Comunicação e Sociedade, Instituto de Ciências Sociais, Campus de Gualtar, 4710-057 Braga, Portugal

* Submetido: 14-09-2018

* Aceite: 05-02-2019 